Pak. j. sci. ind. res. Ser. A: phys. sci. 2021 64A(1) 10-18

\title{
Effect of Reinforced Glass Fibre on the Mechanical Properties of Polyamide
}

\author{
Raza Muhammad Khan and Asim Mushtaq* \\ Polymer and Petrochemical Engineering Department, NED University of Engineering \& Technology, \\ Karachi, Sindh, Pakistan
}

(received August 5, 2019; revised December 9, 2019; accepted January 7, 2020)

\begin{abstract}
The aim of this study is to enhance the tensile and flexural strength of polyamide (nylon 6,6) by incorporation of glass fibre. Nylon has high elasticity, strength, toughness and maintain mechanical properties at elevated temperatures. The method employed for enhancement of properties is by the reinforcement of glass fibre. Glass fibre is the most extensively used reinforcement material. It is a lightweight, extremely solid, durable, low cost material that moderafly stiff. The composition of glass fibre was kept at $0 \mathrm{wt.} \%, 30 \mathrm{wt} . \%$ and $50 \mathrm{wt} . \%$ in nylon 6,6 blend. Initially, samples were manufactured by injection molding of nylon 6,6 and glass fibre. The pressure and velocity profiles at $0 \mathrm{wt} . \%, 30 \mathrm{wt} . \%$ and $50 \mathrm{wt} . \%$ reinforced nylon 6,6 are also compared. The samples thus formed were checked for shrinkage. The samples were tested for their tensile and flexural properties. The mechanical properties of polyamide (nylon 6,6) significantly improves by increasing glass fibre reinforcement.
\end{abstract}

Keywords: flexural strength, glass fibre, nylon 6,6, polyamide, tensile

\section{Introduction}

The term nylon is a conventional term used to describe a categery of synthetic polyamides that are synthetic. The amide group (- $\mathrm{CONH}-)$ in nylons forms some portion of the polymer fundamental chain. The chemical structure of nylons are divided into two categories, one based on dibasic acids or diamines and other based on lactams or amino acids. Nylons are referred by a numbering system that reveals the number of carbon atoms in their structure, like nylon 6 represents polycaprolactam (poly. $\omega$-amino caproic acid). In the nylons family, nylon 6 and nylon 6.6 are of the utmost commercial importance as they offer good set of properties with economical cost. Other commercially useful materials like, e.g are nylon 6,9; nylon 6,10; nylon 6,12; nylon 11; and nylon 12 , have relatively higher prices (Pickering et al., 2016).

Nylon 6 and nylon 6,6 have semi-crystalline structure with good durability and strength for challenging applications with their own distinct and separate benefits they do share some core properties such as good fatigue resistance, electrical insulating properties, sliding properties, resistance to high energy radiation, machinability and excellent wear resistance. It also has high mechanical damping ability, mechanical strength,

*Author for correspondence;

E-mail: engrasimmushtaq@yahoo.com. stiffness, hardness and toughness (Pickering et al., 2016; Teixeira et al., 2015).

Althow nylon 6 and nylon 6.6 are very alike materials they also possess some different characteristics, these differences are due to different chemical structure. The nylon 6 consist of one monomer with 6 carbon atoms, while nylon 6,6 has 2 monomers with each one having 6 carbon atoms, therefore named as nylon 6,6 (Saba et al., 2014). Table 1 shows the comparison of different properties of nylon 6 and nylon 6,6. Also, nylon 6 endures high impact stress and stands up to hydrocarbons well while nylon 6,6 has improved stiffness, tensile and flexural modulus. Nylon 6,6 is a very common engineering thermo plastic used in plastic processing. Nylon 6,6 can be used with a different composition according to the requirement of the product. It shows very high flow in thin sections and has good weld

Table 1. Comparison of different properties of nylon 6 and nylon 6,6

\begin{tabular}{lll}
\hline \hline Properties & Nylon 6 & Nylon 6,6 \\
\hline Crystallinity & Less & More \\
Mold shrinkage & Lower & Higher \\
Melting point & Lower & Higher \\
Heat deflection temperature & Lower & Higher \\
Water absorption rate & High & Lower \\
Chemical resistance & Poor & Better \\
\hline \hline
\end{tabular}


strength. It is a hygroscopic compound and pre-drying is important. The crystalline melting point of nylon is $265^{\circ} \mathrm{C}$. It shows very high resistance towards wear because of its very high molecular weight. The major application of nylon includes nylon fibre, clothing, footwear, panty house, tooth brush bristles, finishing lines, air bag fibre, parachutes machine parts such as gears and bearing (Frihi et al., 2016).

The aim of this study is to use reinforced nylon 6,6 with 0 wt. $\%, 30$ wt. $\%$ and 50 wt. $\%$ glass fibre and injection molding and to identify the difference in pressure and velocity profile, when used with three different glass fibre reinforcements by a graphical representation. In addition, the shrinkage factors, tensile strength, elongation modulus, elongation at break, flexural stress, flexural strain and flexural modulus for all the three reinforcements of glass fibre, will be discussed.

\section{Materials and Methods}

Polyamide and Nylon 6, 6 glass fiber reinforcments (toughness, low coefficient of friction, and good abrasion resistance) were purchased from Merck, Germany.

Injection molding. Injection molding is very common and popular in plastic processing techniques, in which molten material is injected into the cavity, allowing the material to cool down and solidify and eject the material. There are many ejection systems used to eject the material like pin ejection, sleeve ejection, air ejection, which depending upon the nature of the product and mold. Normally the injection molding machine is divided into two parts provided with the mold between injection and clamping unit (Nagakura et al., 2017). The injection unit consists of a screw motor, a barrel, a hopper, a heater band, a stationary plate and aninjection nozzle. The Barrel plays a vital role in the method of injection moulding process. It is also called the heating cylinder. Normally, it is made of an inexpensive grade of steel. The barrel is supported by an electrically activated heater band. Normally, the barrel is divided into three zones, unusual centre and front. The temperature is comparatively low in the rare zone and increasing consistently in the centre and front zone. The injection screw is placed inside the barrel. Screw design is very important in polymer processing and it may vary from material to material. The hopper is the component, where the plastic material is initially stored before it is injet to the barrel, its size depends on the machine size.
Sometimes hopper is supported by dryer for drying of the material which is hygroscopic. The nozzle is the final component of the injection unit. The molten plastic is injected into the mold cavity with the help of a nozzle. A heater band is provided at the nozzle tip known as nozzle heater (Nagakura et al., 2017). The basic purpose of the clamping unit is to grip the mold throughout the injection process. The pressure in the clamping unit should be equal to the injection unit. The clamping unit normally has three types of systems, toggle or mechanical, hydraulic and third is the combination of mechanical and hydraulic clamping (Pickering et al., 2016).

Parameters of the injection molding process. In injection molding different parameters affect the product quality. Main processing parameters of the injection molding, process are temperature, pressure, time and distance. The variation in the temperature affects the injection molding process and the quality of the final product. It may include the melt temperature, mold temperature and even the ambient temperature. The melt temperature is normally maintained throughout the flow path, which starts from the hopper to machine barrel, then from machine barrel to nozzle. From the nozzle, it is injected into the mold cavity. The heating barrel has three zones, rear zone, centre zone and front zone. The temperature is gradually increases from the rear zone to front zone. The control of melt temperature is very important. The melting temperature of nylon 6 is $215^{\circ} \mathrm{C}$ to $220^{\circ} \mathrm{C}$ and nylon 6,6 is $274{ }^{\circ} \mathrm{C}$ to $280{ }^{\circ} \mathrm{C}$. After melting in the barrel, the material is now ready to flow into the mold, where the material will cool down. The cooling rate depends upon the material and the design of the product. The mold temperature of nylon 6 is $93{ }^{\circ} \mathrm{C}$ and nylon 6,6 is $79{ }^{\circ} \mathrm{C}$ (Essabir et al., 2018; Saba et al., 2014). Injection molding machines comprise of two units, injection and clamping unit. Both the two units require pressure and pressure control. The pressure in the clamp unit is required to overcome the pressure of the injection unit. There are three basic types of pressures in the injection unit, which are the initial injection, holding and backup pressures. The initial pressure is used to push the molten plastic. It is normally operated by hydraulic pressure. As a result of this pressure, the initial filling of the mold takes place. The holding pressure is also called secondary pressure, it is used with molten plastic for the final filling of the mold and holds it till the molten plastic solidifies. Shrinkage factor has been reduced by holding pressure. 
Holding pressure is used to finish the filling of the mold. After the holding pressure, the back pressure is applied to the machine. Usually, the back pressure is small as compared to injection pressure. The back pressure is used to control the part weight, density and product appearance. During the injection process in the clamping unit, pressure is used to close the mold. The amount of injection and clamp force must be equal (Palazzetti, 2015).

Injection molding of nylon 6, 6. In the lab, the nylon 6,6 is used for experimental work and for the processing in injection moulding machine to make the test specimen for the tensile and flexural test. Nylon 6, 6 is taken with three different reinforcements of glass fibre that is nylon 6,6 with o wt.\% glass fibres. Nylon 6,6 with 30 wt.\% glass fibre and nylon 6,6 with 50 wt. $\%$ glass fibre. Table 2 shows the injection molding process parameters.

Shrinkage calculations. Shrinkage is calculated for tensile and flexural bar produced specimens by taking the difference of mold dimensions and specimen dimensions. The dimension of the mold cavity is measured by micro meter screw gauge when the width is $10.05 \mathrm{~mm}$ and thickness $2.39 \mathrm{~mm}$ for tensile bar and width is $10.06 \mathrm{~mm}$ and thickness is $4.03 \mathrm{~mm}$, for flexural bar.

Tensile testing. The tensile test is a mechanical test of the material in which the behaviour of a material is determined under uni axial stretch loading. The

Table 2. Process parameters for injection moulding

\begin{tabular}{|c|c|c|c|c|c|}
\hline Parameters & Units & Zone & $\begin{array}{l}0 \\
\text { wt. } \%\end{array}$ & $\begin{array}{l}30 \\
\text { wt.\% }\end{array}$ & $\begin{array}{l}50 \\
\text { wt.\% }\end{array}$ \\
\hline Barrel temperature $\left({ }^{\circ} \mathrm{C}\right)$ & \multirow[t]{4}{*}{${ }^{\circ} \mathrm{C}$} & \multirow{4}{*}{$\begin{array}{l}1 \\
2 \\
3 \\
4\end{array}$} & \multirow{4}{*}{$\begin{array}{l}310 \\
295 \\
295 \\
280\end{array}$} & \multirow{4}{*}{$\begin{array}{l}310 \\
295 \\
295 \\
280\end{array}$} & \multirow{4}{*}{$\begin{array}{l}310 \\
295 \\
295 \\
280\end{array}$} \\
\hline Nozzle Screw Hopper & & & & & \\
\hline 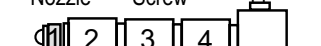 & & & & & \\
\hline 3 & & & & & \\
\hline Mold temperature & ${ }^{\circ} \mathrm{C}$ & - & 93 & 93 & 93 \\
\hline Shot size & $\mathrm{mm}$ & & 36.0 & 36.75 & 38.5 \\
\hline Injection velocity & $\mathrm{mm} / \mathrm{s}$ & & 45 & 45 & 45 \\
\hline Transfer position & $\mathrm{mm}$ & & 10 & 10 & 10 \\
\hline Packing pressure & bar & & 375 & 375 & 375 \\
\hline Packing time & $\mathrm{sec}$ & & 19 & 19 & 19 \\
\hline $\begin{array}{l}\text { Decompression } \\
\text { distance }\end{array}$ & $\mathrm{mm}$ & & 3 & 3 & 3 \\
\hline $\begin{array}{l}\text { Plasticization screw } \\
\text { speed rpm }\end{array}$ & & & 75 & 75 & 75 \\
\hline $\begin{array}{l}\text { Plasticization back } \\
\text { pressure }\end{array}$ & bar & & 50 & 50 & 50 \\
\hline Cooling time & $\mathrm{sec}$ & & 15 & 15 & 15 \\
\hline
\end{tabular}

elongation, elastic modulus, tensile strength and yield strength and other properties can be measured by using the data of the test. It is a quiet simple test to get a good tensile profile. The point of failure is normally referred to as ultimate strength. The stress $\sigma$ (have been calculated by eq. (1). Figure 1 represents the specimens used for tensile testing manufactured on injection molding.

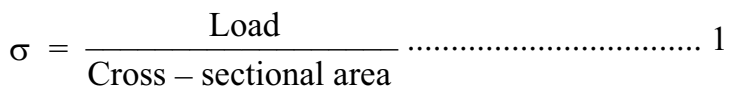

The ratio of stress and strain is called Hook's Law, which is normally constant and determined by eq. (2).

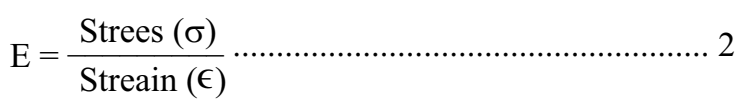

When the stress is proportional to strain, then it is called modulus of elasticity. The stiffness of the material is measured by the modulus of elasticity. It is the linear region of the curve. At this point, some permanent deformation starts to occur in the specimen. This point is normally referred to as proportional limit. At this point when the stress is removed, the material will not come to its original position. The 30 different samples have been tested for tensile properties. In these 30 samples, 10 samples are reinforced with 0 wt. \% glass fibre, 10 samples with $30 \mathrm{wt}$. \% glass fibre reinforcement and remaining 10 are $50 \mathrm{wt}$ \% reinforced with glass fibre as shown in Table 3. All these specimens are manufactured on injection molding.

Flexural testing. The ability of a material to withstand bending forces applied perpendicular to its longitudinal axisis known as flexural strength. Flexural strength is

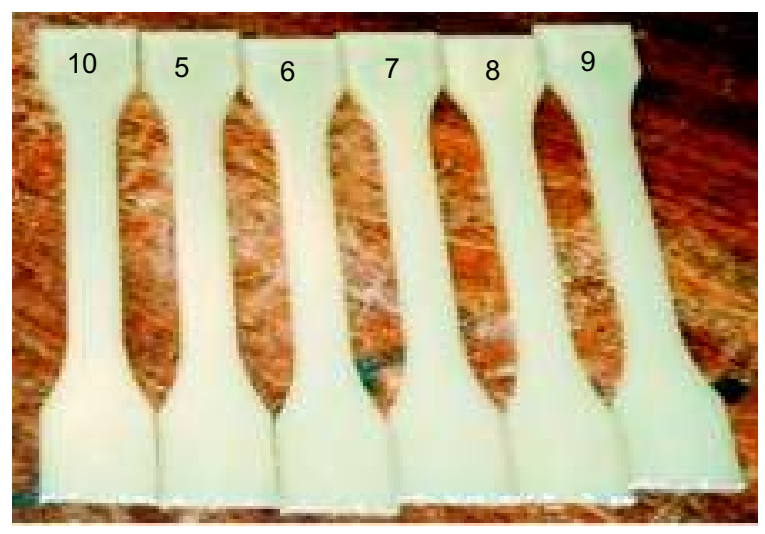

Fig. 1. Specimens used for tensile testing manufactured on injection molding. 
Table 3. Tensile test data for 0 wt. $\%, 30$ wt. $\%$ and 50 wt.\% glass fibre reinforcement

\begin{tabular}{|c|c|c|c|c|}
\hline Sample & Glass fibre & $\begin{array}{l}\text { Time 'sec' } \\
\text { wt.\% }\end{array}$ & Load 'N' & $\begin{array}{l}\text { Stroke } \\
\text { 'mm' }\end{array}$ \\
\hline 1 & \multirow[t]{10}{*}{0} & 34929.11 & 1018.36 & 2.879 \\
\hline 2 & & 151730.5 & 1441.056 & 12.61 \\
\hline 3 & & 135479.8 & 1428.059 & 11.263 \\
\hline 4 & & 138029.9 & 1424.617 & 11.476 \\
\hline 5 & & 122529.7 & 1428.608 & 10.179 \\
\hline 6 & & 35079.11 & 1011.957 & 2.891 \\
\hline 7 & & 115629.8 & 1384.97 & 9.609 \\
\hline 8 & & 120380.5 & 1418.92 & 10.005 \\
\hline 9 & & 150079.9 & 1450.82 & 12.483 \\
\hline 10 & & 28029.25 & 2453.26 & 2.309 \\
\hline 11 & \multirow[t]{10}{*}{30} & 28029.25 & 2453.26 & 2.309 \\
\hline 12 & & 26829.21 & 2430.266 & 2.209 \\
\hline 13 & & 27929.24 & 2473.81 & 2.3 \\
\hline 14 & & 34899.34 & 2401.206 & 2.879 \\
\hline 15 & & 30428.97 & 2476.67 & 2.504 \\
\hline 16 & & 31130.45 & 2045.78 & 2.563 \\
\hline 17 & & 29629.26 & 2473.58 & 2.443 \\
\hline 18 & & 30732.06 & 2437.1 & 2.53 \\
\hline 19 & & 35099.34 & 2253.21 & 2.89 \\
\hline 20 & & 29829.29 & 2381.32 & 2.459 \\
\hline 21 & \multirow[t]{10}{*}{50} & 29799.22 & 3511.43 & 2.454 \\
\hline 22 & & 29479.28 & 3446.68 & 2.430 \\
\hline 23 & & 34979.4 & 318.82 & 2.888 \\
\hline 24 & & 29401.51 & 3411.74 & 2.421 \\
\hline 25 & & 32129.34 & 3398.74 & 2.651 \\
\hline 26 & & 30428.97 & 3321.25 & 2.504 \\
\hline 27 & & 30529.31 & 3363.39 & 2.571 \\
\hline 28 & & 31198.93 & 3374.27 & 2.566 \\
\hline 29 & & 34429.09 & 3270.99 & 2.837 \\
\hline 30 & & 27780.68 & 3400.44 & 2.288 \\
\hline
\end{tabular}

the combination of different stresses which include tensile stresses and compressive stresses. The calculation of flexural properties is done regarding stress and strain. Many polymers do not break, while testing flexural properties because it is a bending test and deflection is observed in these kinds of test. Three-point bending and four-point bending methods are used to determine the flexural properties. Normally the three-point bending method is used for the material which shows small deflection and four-point bending methods is used for the material which shows larger deflection during testing. In the flexural test the maximum stress can be obtained by the eq.(3) (Withers et al., 2015).

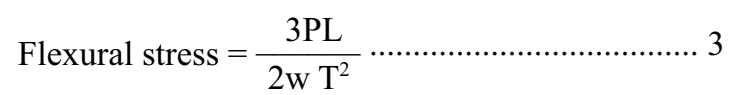

where:
' $\mathrm{P}$ ' denotes the load, ' $\mathrm{L}$ ' represents length of span, ' $\mathrm{w}$ ' indicate the width of the specimen and ' $\mathrm{T}$ ' for the thickness of the specimen. The flexural strain is calculated by the eq. (4).

Flexural strain $=\frac{6 \mathrm{DP}}{\mathrm{L}^{2}} \cdots \cdots \cdots \cdots \cdots \cdots \cdots \cdots \cdots \cdots \cdots \cdots \cdots \cdots \cdots \cdots \cdots \cdots \cdots \cdots \cdots$

where:

' $\mathrm{D}$ ' is the deflection, ' $\mathrm{T}$ ' is the thickness of the specimen and ' $\mathrm{L}$ ' is the length of the span.

While, doing the flexural test, specimen preparation, temperature and test conditions may affect the test results. It is also called flexural modulus that measures the stiffness of material during the first bending process as given in eq. (5) (Chaichanawong et al., 2016). The procedure for calculating the flexural modulus is quite

Table 4. Flexural test data for 0 wt. $\%, 30$ wt. $\%$ and 50 wt. \% glass fibre reinforcement

\begin{tabular}{|c|c|c|c|c|}
\hline Sample & $\begin{array}{l}\text { Glass fibre } \\
\text { wt. } \%\end{array}$ & Time 'sec' & Load 'N' & $\begin{array}{l}\text { Stroke } \\
\text { 'mm' }\end{array}$ \\
\hline 31 & 0 & 35229.4 & 8.25267 & 2.91058 \\
\hline 32 & & 32381.41 & 8.22894 & 2.6735 \\
\hline 33 & & 31229.32 & 7.86097 & 2.57932 \\
\hline 34 & & 30581.1 & 8.25847 & 2.52349 \\
\hline 35 & & 30879.35 & 8.269 & 2.54832 \\
\hline 36 & & 30899.25 & 7.355 & 2.54829 \\
\hline 37 & & 30629.31 & 7.95389 & 2.52766 \\
\hline 38 & & 30679.31 & 7.44169 & 2.53162 \\
\hline 39 & & 30979.32 & 7.51479 & 2.55683 \\
\hline 40 & & 36749.37 & 8.63706 & 3.03536 \\
\hline 41 & 30 & 31079.32 & 26.2042 & 2.56495 \\
\hline 42 & & 36680.14 & 31.9799 & 3.03193 \\
\hline 43 & & 30799.25 & 26.1726 & 2.53953 \\
\hline 44 & & 30979.32 & 26.148 & 2.55662 \\
\hline 45 & & 30680.81 & 26.8317 & 2.53116 \\
\hline 46 & & 31279.33 & 27.0856 & 2.5814 \\
\hline 47 & & 30648.91 & 25.62 & 2.52244 \\
\hline 48 & & 30978.87 & 26.632 & 2.55164 \\
\hline 49 & & 30678.98 & 25.2232 & 2.52682 \\
\hline 50 & & 30978.99 & 25.5128 & 2.55161 \\
\hline 51 & 50 & 31069.19 & 46.0038 & 2.56078 \\
\hline 52 & & 31579.56 & 47.7945 & 2.60606 \\
\hline 53 & & 20828.85 & 32.1127 & 3.36771 \\
\hline 54 & & 30599.24 & 45.4467 & 2.52328 \\
\hline 55 & & 30749.25 & 45.6067 & 2.53599 \\
\hline 56 & & 30728.98 & 45.6265 & 2.53078 \\
\hline 57 & & 31059.39 & 46.5317 & 2.56432 \\
\hline 58 & & 30979.32 & 46.2518 & 2.55662 \\
\hline 59 & & 30929.32 & 46.7502 & 2.55203 \\
\hline 60 & & 30928.99 & 45.7217 & 2.54744 \\
\hline
\end{tabular}


similar to the procedure of calculating tensile modulus. In many cases values of flexural modulus and tensile modulus are same. The 10 samples of Nylon 6,6 with glass fibre reinforcement of $0 \mathrm{wt} . \%, 30 \mathrm{wt} . \%$ and 50 wt.\% were used for flexural testing. All these test bars were manufactured on injection molding. Table 4 represents the flexural test data for $0 \mathrm{wt} . \%, 30 \mathrm{wt} . \%$ and $50 \mathrm{wt} . \%$ glass fibre reinforcement.

Flexural modulus $=\frac{\text { Flexural stress }}{\text { Flexural strain }} \ldots \ldots \ldots \ldots \ldots \ldots \ldots . . . . . . .5$

\section{Results and Discussion}

Pressure-velocity profile. According to the data provided for processing of nylon 6,6 it looks quite similar as shown in Table 2 for all the three materials, but certain differences changes have been observed in pressure velocity profile, which is shown in Fig. 2.

When nylon 6,6 is used with 0 wt.\% glass fibre reinforcement, the initial injection pressure is not very high. That means low injection pressure is required to fill the mold cavity initially, then the pressure drops and constant holding pressure is applied to the mold. When the nylon is used with $30 \mathrm{wt} . \%$ glass fibre reinforcement, the initial injection pressure is quite higher as compared to the pressure that was observed in the processing of nylon 6,6 with $0 \mathrm{wt} . \%$ glass fibre reinforcement. However, the holding pressure looks constant for both the material but a wide difference has been observed between the initial injection pressure and holding pressure. When nylon 6,6 is used with 50 wt.\% glass fibre reinforcement the initial injection

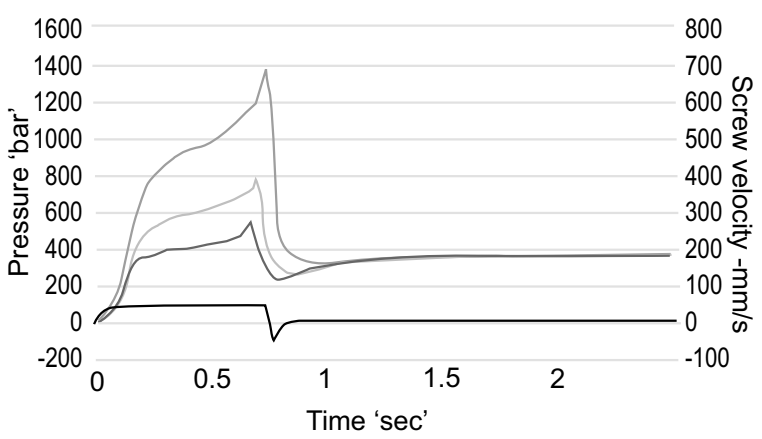

- 0\% Pressure - bar - 30\% Pressure - bar

$-50 \%$ Pressure - bar - Screw velocity $-\mathrm{mm} / \mathrm{s}$

Fig. 2. Pressure-velocity profile comparison of nylon 6,6 with 0 wt. $\%, 30$ wt. $\%$ and 50 wt.\% glass fibre reinforcement. pressure is relatively very high as compare to $0 \mathrm{wt} . \%$ and $30 \mathrm{wt} . \%$ glass fibre reinforcement. It was observed that increasing $\%$ glass fibre reinforcement would increase the initial pressure for pushing molten plastic to the mold cavity. This is because the melt viscosity will gradually increase due to the higher crystallinity in nylon 6,6 structure as two monomers contain 6 carbon atoms for each. The findings are accordance with the previous literature (Garcia et al., 2018; Fernandes et al., 2017; Bernasconi et al., 2015).

Shrinkage for tensile and flexural bar. Figures 3 and 4 representing the results for both tensile and flexural bars revealed that, the $\%$ of shrinkage increases with the increase is glass fibre reinforcement in both the direction that is in width and thickness. The mould

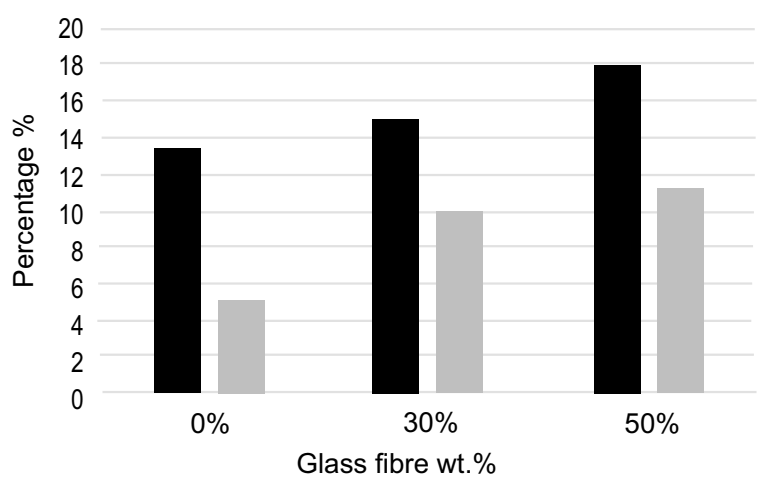

$\%$ Shrinkage in width $\%$ Shrinkage in thickness

Fig. 3. Comparison between the percentage of shrinkage in width and thickness for the specimens of the tensile test.

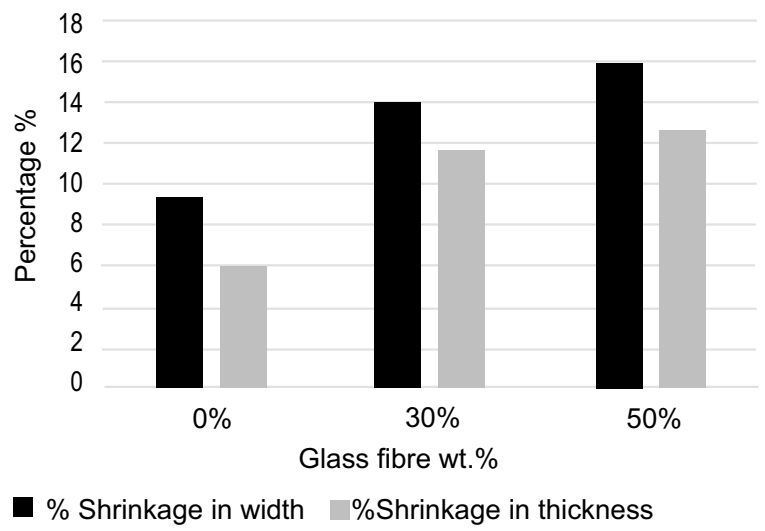

Fig. 4. Comparison between percentage shrinkage in width and thickness for the specimens of flexural test. 
shrinkage of nylon 6,6 is further incresed by the rebonding of glass fibre during the injection process and bonding strength has been increased. Table 5 is the summarized form of shrinkage results for tensile and flexural bar specimen with 0 wt. \%, 30 wt. \%, 50 wt. $\%$ glass fibre reinforcement. The present research work traced by the previous work.

The mechanical property of glass fibre filled polyamide composites are directed by the distinct properties of the fibre and blend, along with a multifaceted incorporation of some parameters such as fibre size, content, distribution and orientation, as well as physicochemical collaborations at the polymer-fiber interface (Graupner et al., 2016; Arif et al., 2014; Feldmann and Bledzki, 2014).

Tensile result of glass fibre reinforcement. Figure 5 represents the specimen of Nylon 6,6 with 0 wt. $\%, 30$ wt. $\%$ and $50 \mathrm{wt} . \%$ glass fibre reinforcement after tensile testing. The obtained results revealed that with increasing the amount of glass fibre the tensile strength and elastic modulus is increasing significantly, whereas \% elongation is decreasing as shown in Fig. 6 to 8. This means increasing the amount of glass fibre, increases the strength of the final product. The tensile test results for $0 \mathrm{wt.} \%, 30 \mathrm{wt} . \%$, and $50 \mathrm{wt} . \%$ glass fibre reinforcement are shown in Table 6.

Table 5. Shrinkage results for tensile and flexural bar specimen with 0 wt. $\%, 30$ wt. $\%$ and 50 wt. $\%$ glass fibre reinforcement

\begin{tabular}{llllll}
\hline \hline $\begin{array}{l}\text { Shrinkage } \\
\text { calculation }\end{array}$ & $\begin{array}{l}\text { Glass } \\
\text { fibre } \\
\text { wt. } \%\end{array}$ & $\begin{array}{l}\text { Width } \\
\text { 'mm' }\end{array}$ & $\begin{array}{l}\text { Thickness } \\
\text { 'mm' }\end{array}$ & $\begin{array}{l}\% \\
\text { Shrinkage } \\
\text { in width }\end{array}$ & $\begin{array}{l}\text { Shrinkage } \\
\text { in } \\
\text { thickness }\end{array}$ \\
\hline Tensile bar & 0 & 9.914 & 2.34 & 13.6 & 5 \\
& 30 & 9.90 & 2.29 & 15 & 10 \\
& 50 & 9.87 & 2.279 & 18 & 11.1 \\
Flexural bar & 0 & 9.967 & 3.971 & 9.3 & 5.9 \\
& 30 & 9.92 & 3.914 & 14 & 11.6 \\
& 50 & 9.903 & 9.903 & 15.7 & 12.6 \\
\hline \hline
\end{tabular}

According to the literature percentage elongation decreases due to rigid fibres restrain matrix deformation persuading strength gain and brittleness of the resultant

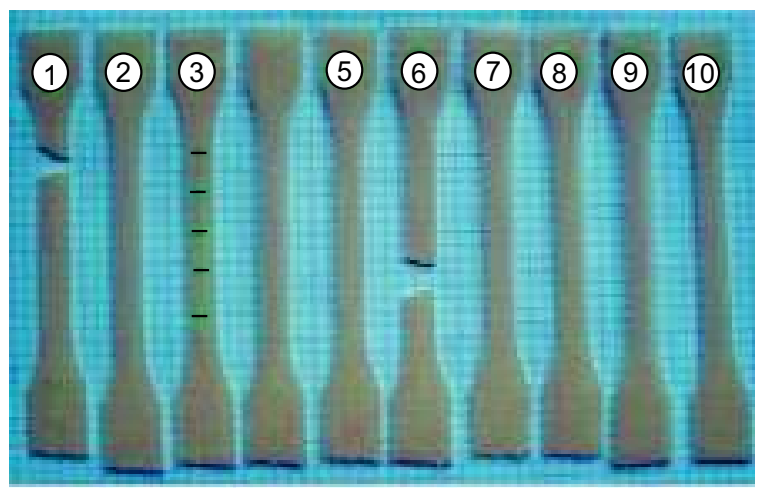

(a)

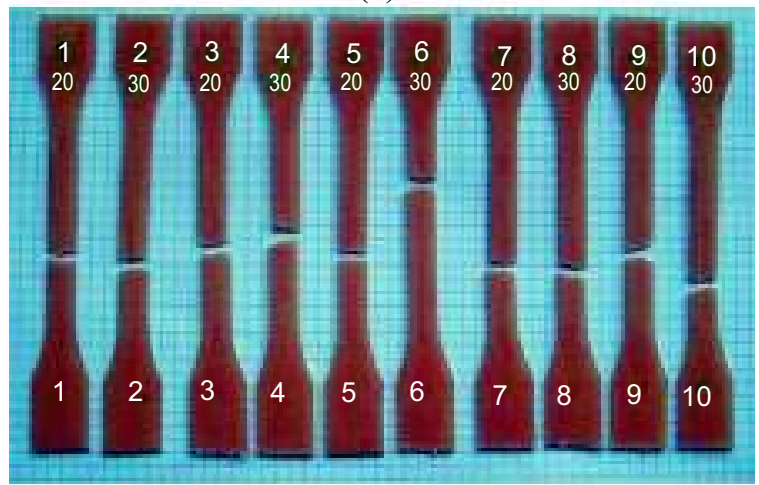

(b)

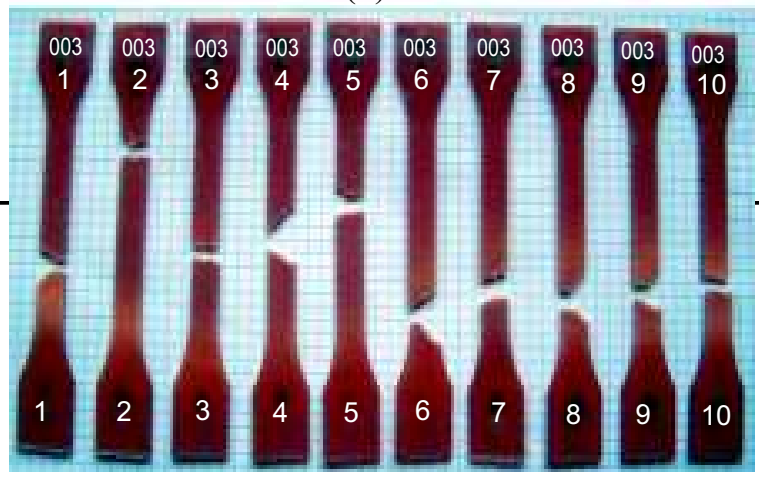

(c)

Fig. 5. Specimen of nylon 6, 6 with (a) 0 wt.\%, (b) 30 wt.\% and (c) 50 wt.\% glass fibre reinforcement after tensile test.

Table 6. Tensile test results for $0 \mathrm{wt} . \%, 30 \mathrm{wt.} \%$ and $50 \mathrm{wt} . \%$ glass fibre reinforcement

\begin{tabular}{lllllllc}
\hline \hline $\begin{array}{l}\text { Glass fibre } \\
\text { reinforcement wt. \% }\end{array}$ & $\begin{array}{l}\text { Load 'P' } \\
\mathrm{N}\end{array}$ & $\begin{array}{l}\text { Width 'w' } \\
\mathrm{m}\end{array}$ & $\begin{array}{l}\text { Thickness 'T' } \\
\mathrm{m}\end{array}$ & $\begin{array}{l}\text { Tensile strength } \\
\mathrm{M} . \mathrm{Pa}\end{array}$ & Strain & $\begin{array}{l}\text { \%Elongation } \\
\text { Elastic modulus } \\
\mathrm{G} . \mathrm{Pa}\end{array}$ \\
\hline 0 & 1450.82 & 0.009914 & 0.00234 & 62.53 & 0.24966 & 24.966 & 0.250 \\
30 & 2401.20 & 0.00990 & 0.00229 & 105.915 & 0.05758 & 5.758 & 1.839 \\
50 & 3411.74 & 0.00987 & 0.002279 & 151.68 & 0.04842 & 4.842 & 3.132 \\
\hline \hline
\end{tabular}




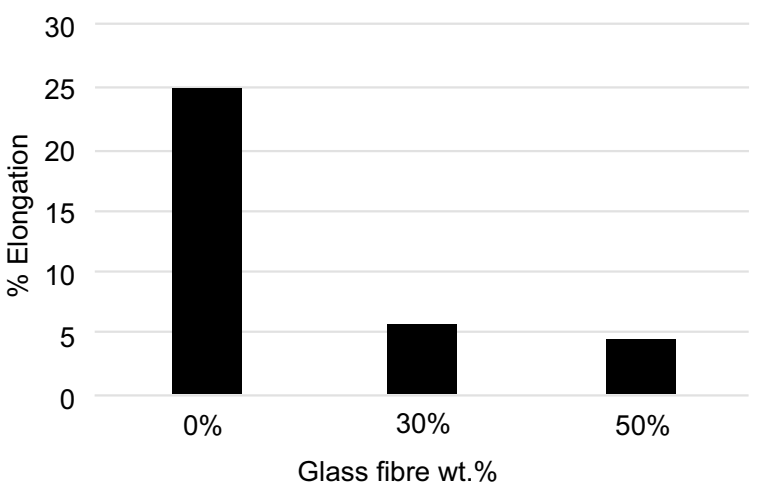

Fig. 6. Effect of \% elongation for three sample of nylon with different wt. \% reinforcement of glass fibre.

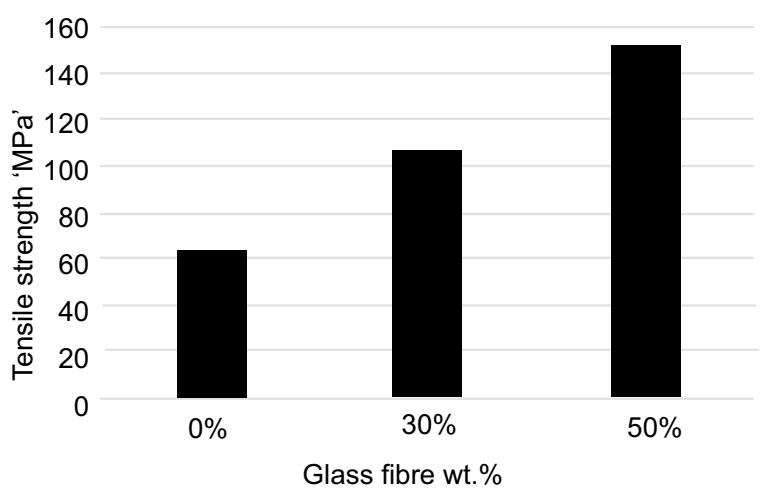

Fig. 7. Effect of tensile strength for three sample of nylon with different wt. \% reinforcement of glass fibre.

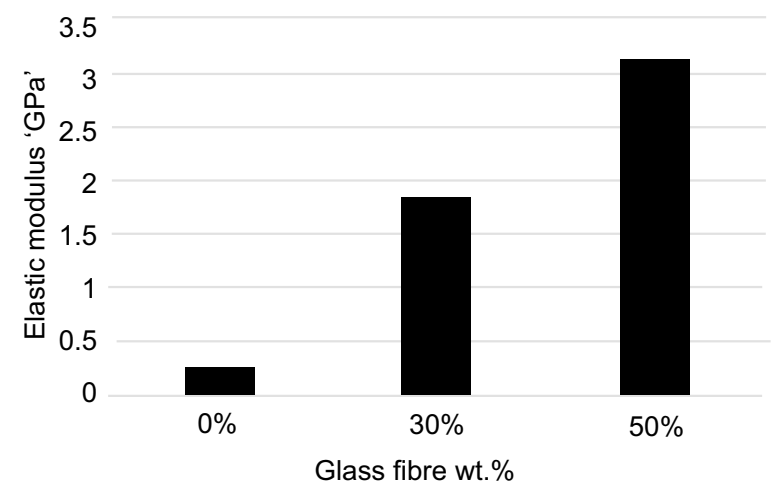

Fig. 8. Effect of elastic modulus for three sample of nylon with different wt. \% reinforcement of glass fibre.

composites. Usually in polymer composites, glass fibres are used to increases the tensile properties. Numerous studies about glass fibre reinforced polymers have reported that increasing composition of glass fibre in the matrix (nylon 6,6), interfacial interactions leads to better load transfer. On the whole, the absence of agglomeration shows good affinity among the glass fibre and the nylon 6,6, that indicates good manufacturing conditions were used (Graupner et al., 2016; Ning et al., 2015; Sethi and Ray, 2015).

The nylon 6,6 with $50 \mathrm{wt} . \%$ glass fibre reinforcement represent high tensile strengths and elastic modulus. The highest value of strength and modulus were perceived for the glass fibre composites, attributable to higher strength, stiffness, better interfacial bonding of glass fibre (Basso et al., 2019; Mortazavian and Fatemi, 2015).

Flexural result of glass fibre reinforcement. Figure 9 shows that as the amount of glass fibre increases in nylon 6,6 , the value of flexural modulus increases. When nylon 6,6 is used with 0 wt.\% glass fibre reinforcement, the value for flexural modulus is very low, but it increases significantly. It means that stiffness of the material increases with the increase in glass fibre. Table 7, represents the summarized form of flexural test results for $0 \mathrm{wt} . \%, 30 \mathrm{wt} . \%$, and $50 \mathrm{wt} . \%$ glass fibre reinforcement.

The reinforcement of glass fibre in the nylon 6,6 led to a change in mechanical properties also depending on the temperature and running conditions. This is anticipated as a result of the high modulus of glass fibre. However, all the results proved that nylon 6,6 make the interactions amongst the components stronger and this is proved by the solid-like behaviour of the composite at higher composition of glass fibre. The

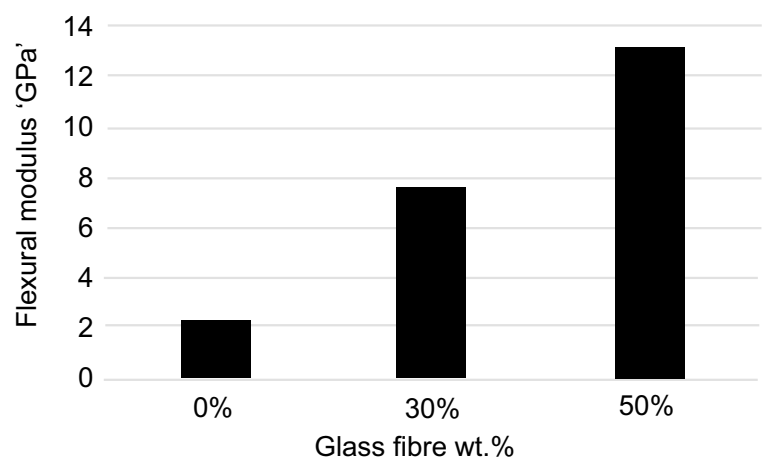

Fig. 9. Effect of flexural modulus on three sample of nylon with different wt. \% reinforcement of glass fibre 
Table 7. Flexural test results for $0 \mathrm{wt.} \%, 30 \mathrm{wt} \% \%$ and $50 \mathrm{wt} . \%$ glass fibre reinforcement

\begin{tabular}{|c|c|c|c|c|c|c|c|}
\hline $\begin{array}{l}\text { Glass fiber } \\
\text { reinforcement } \\
\text { wt. } \%\end{array}$ & $\begin{array}{l}\text { Load 'P' } \\
\mathrm{N}\end{array}$ & $\begin{array}{l}\text { Width 'w' } \\
\text { m }\end{array}$ & $\begin{array}{l}\text { Thickness ' } \mathrm{T} \text { ' } \\
\mathrm{m}\end{array}$ & $\begin{array}{l}\text { Length 'L' } \\
\mathrm{m}\end{array}$ & $\begin{array}{l}\text { Flexural stress } \\
\text { M. Pa }\end{array}$ & Flexural strain & $\begin{array}{l}\text { Flexural modulus } \\
\mathrm{M} . \mathrm{Pa}\end{array}$ \\
\hline 0 & 8.25847 & 0.00996 & 0.00397 & 0.12 & 9.46 & 0.00417 & 2268.58 \\
\hline 30 & 26.1726 & 0.00992 & 0.00389 & 0.12 & 31.384 & 0.004116 & 7624.59 \\
\hline 50 & 45.7217 & 0.00991 & 0.0039 & 0.12 & 54.599 & 0.004139 & 13189.47 \\
\hline
\end{tabular}

results obtained are in good agreement with previous literature concerning fiber reinforced composite (Garcia et al., 2018; Nagakura et al., 2017; Mortazavian and Fatemi, 2015).

\section{Conclusion}

In this study shrinkage calculations gave an approximate result that shrinkage regarding width and thickness increases from 0 wt. \% to 50 wt.\% samples. It was found that as percentage reinforcement increases percentage shrinkage increases at a lesser rate. The penultimate tensile test and its succeeding calculations declared that the tensile strength and elastic modulus significantly increased from $0 \mathrm{wt} . \%$ to $50 \mathrm{wt} . \%$ samples, whereas percentage elongation decrease. Synonymously, the concluding flexural test and its succeeding calculations showed a significant increase in flexural strength and flexural modulus from $0 \mathrm{wt} . \%$ to $50 \mathrm{wt} . \%$ glass fibre reinforced polyamide samples. Hence, it was concluded that mechanical properties of polyamide (nylon 6,6) significantly improve by increasing glass fibre reinforcement. The future recommendation is, shrinkage can be lowered by varying packing or holding pressure to changing in process parameters. Talc also can be used as reinforced material since it is cheap and will provide ease in processing.

\section{Acknowledgement}

The authors would like to acknowledge the Department of Polymer and Petrochemical Engineering, NED University of Engineering \& Technology, Karachi, Pakistan for supporting this research work.

Conflict of Interest. The authors declare no conflict of interest.

\section{References}

Arif, M.F., Saintier, N., Meraghni, F., Fitoussi, J., Chemisky, Y. 2014. Multiscale fatigue damage characterisation in short glass fiber reinforced polyamide-66. Composites Part B: Engineering, 61: $55-65$.

Basso, M., Piselli, A., Simonato, M., Furlanetto, R., Pupure, L. 2019. Effect of food chemicals and temperature on mechanical reliability of bio-based glass fibers reinforced polyamide. Composites Part B: Engineering, 157: 140-149.

Bernasconi, A., Conrado, E., Hine, P. 2015. An experimental investigation of the combined influence of notch size and fibre orientation on the fatigue strength of a short glass fibre reinforced polyamide 6. Polymer Testing, 47: 12-21.

Chaichanawong, J., Thongchuea, C., Areerat, S. 2016. Effect of moisture on the mechanical properties of glass fiber reinforced polyamide composites. Advanced Powder Technology, 27: 898-902.

Essabir, H., Rodrigue, D., Bouhfid, R., Qaiss, A.E.K. 2018. Effect of nylon 6 (PA6) addition on the properties of glass fiber reinforced acrylonitrilebutadiene-styrene. Polymer Composites, 39: 14-21.

Feldmann, M., Bledzki, A.K. 2014. Bio-based polyamides reinforced with cellulosic fibres processing and properties. Composites Science and Technology, 100: 113-120.

Fernandes, F.C., Gadioli, R., Yassitepe, E., Paoli, M.A.D. 2017. Polyamide- 6 composites reinforced with cellulose fibers and fabricated by extrusion: Effect of fiber bleaching on mechanical properties and stability. Polymer Composites, 38: 299-308.

Frihi, D., Layachi, A., Gherib, S., Stoclet, G., MasenelliVarlot, K. 2016. Crystallization of glass-fiberreinforced polyamide 66 composites: Influence of glass-fibre content and cooling rate. Composites Science and Technology, 130: 70-77.

Garcia, C., Trendafilova, I., Zucchelli, A. 2018. The effect of polycaprolactone nanofibers on the dynamic and impact behavior of glass fibre reinforced polymer composites. Journal of Composites Science, 2: 43.

Graupner, N., Albrecht, K., Ziegmann, G., Enzler, H., Müssig, J. 2016. Influence of reprocessing on fibre 
length distribution, tensile strength and impact strength of injection moulded cellulose fibrereinforced polylactide (PLA) composites. Express Polymer Letters, 10: 647-663.

Mortazavian, S., Fatemi, A. 2015. Effects of fibre orientation and anisotropy on tensile strength and elastic modulus of short fiber reinforced polymer composites. Composites Part B: Engineering, 72: 116-129.

Nagakura, M., Tanimoto, Y., Nishiyame, N. 2017. Effect of fiber content on flexural properties of glass fiberreinforced polyamide- 6 prepared by injection molding. Dental Materials Journal, 36: 415-421.

Ning, F., Cong, W., Qiu, J., Wei, J., Wang, S. 2015. Additive manufacturing of carbon fiber reinforced thermoplastic composites using fused deposition modeling. Composites Part B: Engineering, 80: 369-378.

Palazzetti, R. 2015. Flexural behaviour of carbon and glass fiber composite laminates reinforced with nylon 6,6 electrospun nanofibers. Journal of Composite Materials, 1-7.http://doi.org110.1177/ 0021998314565410.
Pickering, K.L., Efendy, M.G.A., Le, T.M. 2016. A review of recent developments in natural fibre composites and their mechanical performance. Composites Part A: Applied Science and Manufacturing, 83: 98-112.

Saba, N., Tahir, P.M., Jawaid, M. 2014. A review on potentiality of nano filler/natural fiber filled polymer hybrid composites. Polymers, 6: 2247-2273.

Sethi, S., Ray, B.C. 2015. Environmental effects on fibre reinforced polymeric composites: evolving reasons and remarks on interfacial strength and stability. Advance of Colloid Interface Science, 217: 43-67.

Teixeira, D., Giovanela, M., Gonella, L.B., Crespo, J.S. 2015. Influence of injection molding on the flexural strength and surface quality of long glass fibrereinforced polyamide 6.6 composites. Materials and Design, 85: 695-706.

Withers, G.J., Yu, Y., Khabashesku, V.N., Cercone, L., Hadjiev, V.G. 2015. Improved mechanical properties of an epoxy glass-fibre composite reinforced with surface organomodified nanoclays. Composites Part B: Engineering, 72: 175-182. 